\title{
Integrating Economic Analysis into LCA
}

\author{
Gregory A. Norris \\ Sylvatica, Harvard University \\ 147 Bauneg Hill Road, North Berwick, ME 03906 USA
}

\begin{abstract}
In nearly all private industry applications of LCA, the decision making situations which LCA addresses must also eventually take the economic consequences of alternative products or product designs into account. However, neither the internal nor external economic aspects of the decisions are within the scope of developed LCA methodology, nor are they properly addressed by existing LCA tools. This traditional separation of life cycle environmental assessment from economic analysis has limited the influence and relevance of LCA for decision making, and left uncharacterized the important relationships and trade-offs between the economic and life cycle environmental performance of alternative product design decision scenarios. This presentation demonstrates how full-scale, standard methods of LCA can and have been tightly, logically, and practically integrated with standard methods for cost accounting, life cycle cost analysis, and scenario-based economic risk modeling. The result is an ability to take both economic and environmental performance - and their tradeoff relationships - into account in product/process design decision making. We review and compare the design philosophies behind two different tools for integrating economics and LCA, and present illustrative case studies of the application of each to real-world problems.
\end{abstract}

\section{ORIGINS OF THE GAP BETWEEN LCA AND LCC}

In nearly all private industry applications of LCA, the decision making situations which LCA addresses must also eventually take the economic consequences of alternative products or product designs into account. However, neither the internal nor external economic aspects of the decisions are within the scope of developed LCA methodology, nor are they properly addressed by existing LCA tools. The ISO 14040 series of standards for LCA methodology does not address the integration of economic analysis with LCA either.

Why have economic analysis not yet been well-addressed by LCA or its software tools? The probable reason is that despite the similarity of their names, Life Cycle Cost analysis (LCC) and LCA have major methodological differences (see Table I).

The root of their differences is the fact that LCC and LCA are each designed to provide answers to very different questions. Life Cycle Assessment evaluates the relative environmental performance of alternative product systems for meeting the same end-use function, from a broad, societal perspective. Life Cycle Cost evaluates the relative cost-effectiveness of alternative investments and business decisions, from the perspective of an economic decision maker such as a manufacturing firm or a consumer. These differences in their purpose lead to differences in their scope and method.

For one thing, the "life cycles" being addressed by each method are different. LCC analyzes the costeffectiveness of an investment over its economic lifetime, which is related to the usage phase in LCA. The time horizon of an LCC analysis is often even shorter than the usage phase of the investment, and is set by the accounting conventions of the decision maker.

Additional aspects of the LCA life cycle which are absent from LCC include:

- Physical flows which have no direct cost consequences for the decision maker

- Flows into or from any processes other than those of the LCC lifetime

Factors central to LCC which are absent from LCA include:

- Cash flows related to investments in product/process changes

- Costs and revenue streams which are not all proportional to, or even dependent at all upon, physical flows which are modeled in LCAs

- The timing of cash flows (costs and benefits), and the present valuation of these flows

- The risks of costs, and their alteration or avoidance as a function of product/process design options Therefore, properly and fully integrating meaningful economic analysis with Life Cycle Assessment requires going well beyond simply treating economic cost as "just another flow," or as another property of flows, within LCA software. It requires the addition of a time dimension to the modeling; the ability to introduce and work with variables that have no causal dependence upon inventory flows; and the ability to create and work with probabilistic scenarios. 
Table I: Critical Aspects of LCA and LCC - and How They Differ

\begin{tabular}{|c|c|c|}
\hline Tool/Method & LCA & $\mathrm{LCC}$ \\
\hline Objective & $\begin{array}{l}\text { Objective: Compare relative } \\
\text { environmental performance of } \\
\text { alternative product systems for meeting } \\
\text { the same end-use function, from a } \\
\text { broad, societal perspective }\end{array}$ & $\begin{array}{l}\text { Objective: Determine cost-effectiveness of } \\
\text { alternative investments and business } \\
\text { decisions, from the perspective of an } \\
\text { economic decision maker such as a } \\
\text { manufacturing firm or a consumer. }\end{array}$ \\
\hline $\begin{array}{l}\text { Activity Scope of } \\
\text { the addressed } \\
\text { "Life Cycle" }\end{array}$ & $\begin{array}{l}\text { Activity scope of "Life Cycle": supply } \\
\text { chain of processes supporting usage } \\
\text { phase; entire physical usage }\end{array}$ & $\begin{array}{l}\text { Activity scope of "Life Cycle": Activities } \\
\text { directly causing costs or benefits to the } \\
\text { decision maker during the economic life of } \\
\text { the investment as a result of the investment. }\end{array}$ \\
\hline $\begin{array}{l}\text { Flows } \\
\text { Considered }\end{array}$ & $\begin{array}{l}\text { Pollutants, resources, and inter-process } \\
\text { flows of materials and energy. }\end{array}$ & Direct costs and benefits to decision maker \\
\hline $\begin{array}{l}\text { Units for tracking } \\
\text { flows }\end{array}$ & Physical and energy units & Monetary units (e.g., Yen, dollars) \\
\hline $\begin{array}{l}\text { Time treatment } \\
\text { and scope }\end{array}$ & $\begin{array}{l}\text { Timing ignored; all causally linked } \\
\text { flows, and some of their impacts, } \\
\text { collapsed in time and valued equally } \\
\text { regardless of timing }\end{array}$ & $\begin{array}{l}\text { Timing is critical. Present valuing } \\
\text { (discounting) of costs and benefits. Specific } \\
\text { time horizon scope, outside of which costs } \\
\text { and benefits are ignored. }\end{array}$ \\
\hline
\end{tabular}

\section{CONSEQUENCES OF THE GAP BETWEEN LCA AND LCC}

The traditional separation of life cycle environmental assessment from economic analysis has at least three important consequences. First, it limits the influence and relevance of LCA for decision making. A company cannot afford to make product design decisions on strictly an LCA basis, without regard to economics, product performance, etc. Even in an idealized scenario where life cycle environmental performance is the only objective in a product design or selection decision, economics needs to be part of the analysis because there are only limited resources with which to pursue this sole objective. That is, even if we only care about environmental performance, we must consider the variable economics of alternatives, in order to identify the decisions through which our limited resources can achieve the best environmental performance.

Second, a separation of LCA and LCC leaves uncharacterized the important relationships and trade-offs between the economic and life cycle environmental performance of alternative product design decision scenarios. This is the missed opportunity which remains even after a separate cost analysis is performed in parallel with an LCA. It is the result of not integrating economic analysis with LCA. Models which treat both economics and life cycle environmental results simultaneously in an integrated fashion can enable decision makers to examine trade-offs and relationships such as:

- Which modifiable process or product design variables within the system provide the greatest combined economic and environmental leverage?

- What are the incremental costs of environmental improvement for each option, and which provides the greatest environmental improvement per dollar?

- How low must the investment cost for a particular environmental improvement to become cost-effective? Third, the LCA perspective and its results can have important economic relevance for companies, which may be missed when cost analyses neglect LCA's scope and findings. Economic analysis of pollution prevention decisions has demonstrated the importance of bringing site-based "hidden" environmental costs out of overhead in order to identify the most cost-effective decisions (reference Tellus, Green Ledgers, HBR) Economic analysis with an entire life cycle perspective will broaden the discovery of "hidden" cost and revenue impacts that are otherwise neglected in conventional economic analyses. This is especially true when the class of economic considerations includes cost and revenue risks, such as those related to accidents, liabilities, consumer perceptions, etc. 


\section{BRIDGING THE GAP BETWEEN LCA AND LCC}

This section outlines two available approaches to fully bridging the gap, connecting full LCA with full LCC. First we mention that there have been some half-way bridges built in the past, of two sorts. One half-way bridge starts on the LCA side and builds partially towards LCC, by simply adding cost flows into the traditional LCA framework, treating cost flows just like physical flows. This approach does not add to LCA capabilities which are useful in an LCC sense, since it treats costs in ways which conflict with all the aspects of LCC listed in Table I.

Another family of half-way bridges begins on the LCC side, and adds elements of "streamlined" or truncated LCA, such as physical flows from the core company and perhaps some first tier suppliers. This approach lacks the LCA attributes listed in Table I, and so fails to identify decisions which minimize total environmental burdens over the full life cycle.

Half-way bridges are dangerous to travel. Fortunately, there are all-the-way bridges available.

\section{Approach 1: PTLaser}

A first combined solution, called "PTLaser," begins with process modeling which satisfies all the required LCA attributes listed in Table I. To these capabilities it adds the required LCC capabilities listed in Table I. These include the dimension of time, and the ability to assign to any physical flow an unlimited number of different fixed and/or variable cost functions. It also includes the ability to define investment costs and their timing for each alternative, flexible depreciation and tax accounting, and discounting. The analysis satisfies the activity scope requirements of LCC within an LCA-scoped model by adding only the costs borne by the decisionmaking firm.

PTLaser is also designed to provide robust treatment of two additional aspects not listed in Table I which are central to many LCCs of environmental investments: uncertainty and risk. Any and all parameters in the models (physical as well as economic) can be defined as uncertain, even dynamically uncertain. The total influence of all input uncertainties upon each alternative's results is then taken into account, and uncertainties' influence can be compared as well. Second, a scenario-building capability allows inclusion of cost risk models: scenarios which may occur with specified probability (allowed to be dynamic), and whose cost consequences can also be specified as dynamic and uncertain.

Based on the models and inputs from the user, the program calculates life cycle inventories for the modeled system alternatives (LCA results) and provides financial evaluations of all alternatives (LCC results), present valuing costs and benefits. PTLaser is used by multinational corporations, universities, and the US EPA [1].

\section{Approach 2: TCAce}

A second tool has recently been completed by a collaborative effort of ten multinational companies and the American Institute of Chemical Engineers' Center for Waste Reduction Technologies. The collaborative project developed a methodology for "Total Cost Assessment" ([2], [3]).

The project defined 5 cost types as summarized in Table II. Types 1 through 4 are internal costs borne by the company and properly included in an LCC evaluation of investment alternatives. Type 5 costs are "external" costs - costs borne by parties other than the decision making company or the parties with which it is transacting.

Table II: cost types in the AIChE/CWRT Total Cost Assessment Method and TCAce

\begin{tabular}{|l|l|}
\hline Cost Type & Description \\
\hline Type 1: Direct & $\begin{array}{l}\text { Direct costs of capital investment, labor, raw material and waste disposal. May } \\
\text { include both recurring and non-recurring costs. Includes both capital and O\&M costs. }\end{array}$ \\
\hline Type 2: Indirect & $\begin{array}{l}\text { Indirect costs not allocated to the product or process (overhead). May include both } \\
\text { recurring and non-recurring costs. Includes both capital and O\&M costs. }\end{array}$ \\
\hline Type 3: Contingent & $\begin{array}{l}\text { Contingent costs such as fines and penalties, costs of forced clean-up, personal injury } \\
\text { liabilities, and property damage liabilities }\end{array}$ \\
\hline Type 4: Intangible & $\begin{array}{l}\text { Difficult to measure costs, including consumer acceptance, customer loyalty, worker } \\
\text { morale, union relations, worker wellness, corporate image, community relations. }\end{array}$ \\
\hline Type 5: External & Costs borne by parties other than the company (e.g., society). \\
\hline
\end{tabular}


TCAce provides a mechanism for integrating LCC and LCA results within a consistent framework to support holistic decision making, as shown in Figure 1. Users import LCA results from their existing LCA software, and they import traditional economic analysis results from their existing financial accounting systems. TCAce provides the ability to:

1) model contingent and intangible costs and cost scenarios quantitatively and in a manner consistent with existing corporate accounting conventions (e.g., approaches to depreciation, discounting, time horizons, etc.)

2) integrate the results of LCA with cost analyses, optionally computing "Type 5" external costs associated with the inventory results for each option

3) evaluating the consequences of an expanding the cost scope of the organization, bringing in successively the cost risks, less tangible costs, and even potentially the external costs.

TCAce is already helping Fortune 100 companies re-evaluate (and in reported cases, change for the better) millions of dollars' worth of decisions, for both capital investment and product-related decisions. It does this by expanding the decision scope to include conventionally-overlooked factors which may be important. As one company reported, "we always knew those costs were out there, but we had no way of dealing with them on the same basis as our Type 1 and 2 costs."

One of the key ways it achieves this objective is by providing a mechanism for integrating judgments and information from across the company. The TCAce scenario-builder can be used during interactive workshops, bringing together company-wide teams of experts from different departments. These workshops stimulate thinking and yield insights which would not have been generated by company individuals in isolation. TCAce then portrays the dynamic cost and benefit consequences of these insights and integrates them with conventional analyses, broadening perspective and ultimately leading to better decisions.

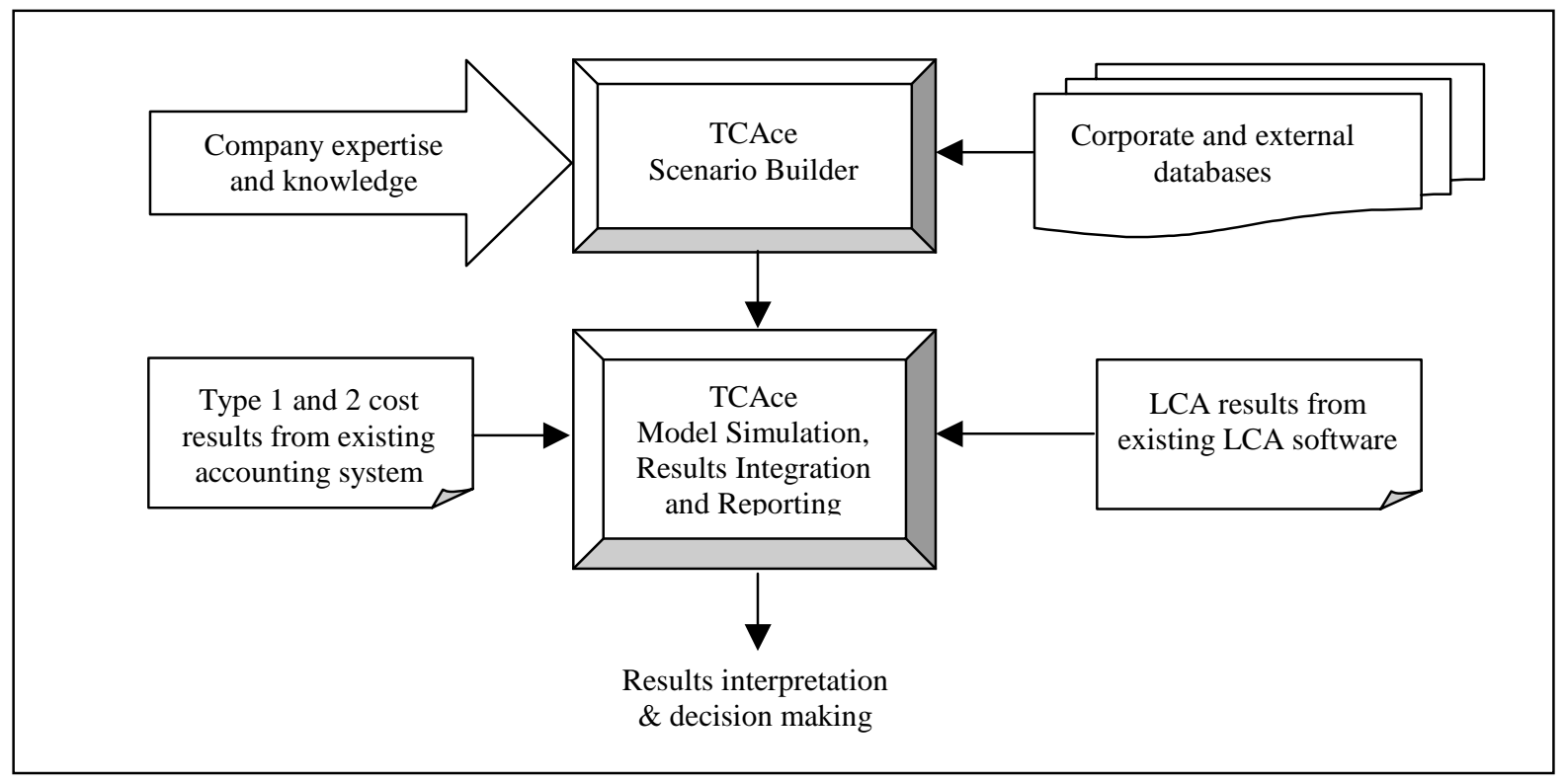

Figure 1: Schematic of TCAce Information Flows

\section{REFERENCES}

\footnotetext{
${ }^{1}$ Further information about PTLaser is available at www.sylvatica.com/tools.htm .

${ }^{2}$ Beaver, Earl, 2000: "LCA and Total Cost Assessment", Environmental Progress, 19(2): 130-139.

${ }^{3}$ CWRT 1999: Total Cost Assessment Methodology, Center for Waste Reduction Technologies, American Institute of Chemical Engineers, New York, NY. (see also: www.aiche.org/cwrt/projects/cost.htm)
} 